\title{
Value-Driven Service Matching
}

\author{
Jaap Gordijn \\ VUA Amsterdam \\ De Boelelaan 1081 \\ 1081 HV Amsterdam \\ The Netherlands \\ gordijn@cs.vu.nl
}

\author{
Sybren de Kinderen \\ VUA Amsterdam \\ De Boelelaan 1081 \\ 1081 HV Amsterdam \\ The Netherlands \\ sdkinde@cs.vu.nl
}

\author{
Roel Wieringa \\ University of Twente \\ P.O. Box 715 \\ 7500 AE Enschede \\ The Netherlands \\ roelw@cs.utwente.nl
}

\begin{abstract}
Electronic service bundles such as Internet access and Voice over IP become increasingly important for the economy. The requirements engineering problem is how to compose an e-service bundle such that consumer needs are met optimally, and the suppliers provide the services economically sustainable. We propose a technique to match a consumer need with a multi-supplier bundle of commercial eservices, which we illustrate by means of a telecommunication case study.
\end{abstract}

\section{Introduction}

In today's economy, the difference between products and services has blurred, and an increasing number of services are commercial e-services that can be ordered and provisioned on-line. E-services are rarely provisioned in isolation but are offered in a bundle, such as Voice over IP (VoIP), Internet access and chat services.

Bundling raises some problems. The customer wants to know which bundles of services are currently on the market, and which of these can satisfy customers' needs. The suppliers would like to offer services that can be provisioned via their technical infrastructure, and with other businesses, and which bundle can be offered in an economically sustainable way.

We propose an approach for suppliers to structure their service catalogues, such that these problems can be addressed, and an intermediary or consumer can find a match between a given consumer need and services offered in supplier catalogues. Consumer requirements need to be elaborated based on the service catalogues and on what consumers find valuable. To do so, we employ marketing theory, by which we can elaborate an initial and incomplete statement of a consumer need and a vague idea of a service that meets this need into a specific consumer demand for a specific service bundle offered by particular suppliers. The resulting match defines a network that connects the consumer with one or more suppliers, in which service delivery and payments are made explicit.

We assume that the concepts defined in this paper are used by a human intermediary who helps a consumer meet a need, or by the consumer himself. In further research, we want support this by software tools.

\section{Running Example}

We use the following case study throughout this paper A consumer wants to communicate with family overseas at low cost and is considering to use VoIP from a telecom provider or from an internet access provider or Instant Messaging (IM) e.g. as offered by Microsoft. Each of these services is bundled with a number of other services, e.g number portation. The question is which bundles are relevant for the consumer, and can be also be provisioned. This example is based on a collaboration we have with a telecom provider (KPN).

\section{Conceptual Framework}

Services and properties. Commercial services are economic activities of a mostly intangible nature [13], with which consumers interact [11, pages 5-9]. We therefore distinguish the interaction that constitutes the service from the means by which this service is provided.

E-services are provisioned by using information technology (IT), having the usual two kind of properties: Functions are useful pieces of interaction, qualities are properties of these interactions. An e-service is a set of functions and quality properties, or a bundle in service marketing.

A quality property can have a value that may satisfy or violate a criterion, as set by the consumer. In case of e.g. 
a bandwidth property, $10 \mathrm{Kbps}$ is a data value of that property, to distinguish it from the consumer value of the property. What suppliers offer in their catalogues are services with functions with qualities. Service functions may have a hierarchical structure, i.e. the interactions of one function may be part of the interactions of a more complicated function.

A supplier property such as "bandwidth" may be called "speed" by a consumer, and the consumer may not understand this property in the same way as the supplier. We simplify our discussion by assuming that properties and criteria have the same meaning, and are described in the same language, by all suppliers and consumers.

Supplier-side (un)bundling. Bundles of (multi-supplier) services may be broken down into smaller pieces if desirable. Qualities however cannot be unbundled from the functions they are properties of. Also, from a commercial viewpoint, a supplier may decide not to unbundle [5].

Therefore, service catalogues should contain constraints on possible bundles. Baida [2, pages 83-84] has identified a number of different kinds of supplier-side constraints, of which we here mention two: $S_{1}$ has a core/supporting relationship with $S_{2}$ if $S_{1}$ cannot be provided (for technical or commercial reasons) without also providing $S_{2}$. The supporting service may be supplied by the same supplier as the supplier of the core service, or it may be supplied by another supplier. $S_{1}$ excludes $S_{2}$ if the supplier of $S_{1}$ prevents the consumer to consume $S_{2}$, for example because $S_{2}$ is offered by a competitor, or because joint consumption is legally prohibited.

Consequences and consumer values. Services have consequences for consumers, which can be valued positively or negatively. Applying the laddering theory [10, 14], our matching approach searches for a net positive consumer valuation that can be achieved by the consequences of service consumption. We then identify the service properties (functions or qualities) enabling these consequences. These service properties are called benefits. Our reasoning from consequences back to properties therefore has a similar structure as the reference model of RE [9]: In consumer context $C$ we search for a bundle $S$ of properties such that consumer value $V$ is realized. To determine whether consequences are valuable for a consumer we use the qualitative framework for consumer value of Holbrook [11].

Consumer needs, wants and demands. The matching process starts with a (problem/need, solution/want) pair. A consumer need is a consumer's desire to realize a consumer value, and a consumer want is an indication of the kind of service that the consumer thinks would partially meet this,

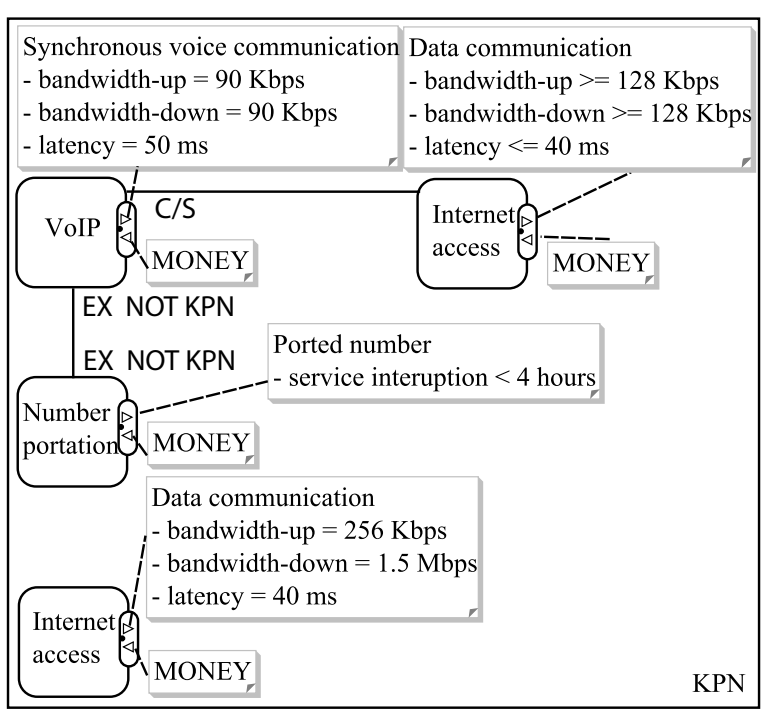

Figure 1. Partial Service catalogue for KPN

without having a specific supplier in mind already $[1,12]$. A need can result in a set of (alternative) wants.

The want is elaborated into a demand: a supplier-specific service bundle the consumer is willing to buy. The difference between a consumer want and a consumer demand is the difference between a vague solution idea and concrete solution offered by a supplier, as available on a market [4]. During this need/want/demand elaboration, constraints may be encountered. The constraints apply to desired consequences. We have encountered four such consumer-side consequence relationships so far: Consequence $C_{2}$ has a core/enhancing relationship with consequence $C_{1}$ if it adds consumer value to $C_{1}$ and can be satisfied by a service that is offered as an optional feature of a more basic service, and which cannot be delivered independently from this basic service. Consequence $C_{1}$ has an optional bundling relationship with consequence $C_{2}$ if both consequences add consumer value to each other. Consequence $C_{1}$ may exclude consequence $C_{2}$ if desiring $C_{1}$ implies not desiring $C_{2}$. Consequence $C_{1}$ depends on consequence $C_{2}$ if $C_{1}$ can only exist if $C_{2}$ exists, e.g. because $C_{1}$ is an attribute of $C_{2}$.

\section{Service catalogues}

To express service catalogues, we use the $e^{3}$-value notation [7] and describe service entries as $e^{3}$-value fragments.

Figure 1 shows the partial catalogue for KPN (two other catalogues can be found in [8]). A supplier is an economic actor, represented by a rectangle with sharp corners in the $e^{3}$-value notation. Service provision activities are represented in $e^{3}$-value as value activities by rectangles with rounded corners. Placement of a service provision activity 
inside a supplier rectangle means that this activity is performed by this supplier. For example, VoIP is a service provision activity performed by KPN. Each service provision activity has a value interface, represented by an oval, through which the service is offered and through which something valuable is accepted in return. A value interface expresses atomicity: If it produces outcomes, it also accepts income.

The service offered by a value activity consists of functions and qualities, which we show by annotating the service arrow in a service interface with the functions and qualities. One service may contain any number of functions and one function may have any number of qualities.

The possible service bundles are subject to supplier-side bundling constraints, represented by binary relationships on service provision activities. For example, VoIP of KPN has a core/supporting $(\mathrm{C} / \mathrm{S})$ relationship with Internet access.

Each value activity provides a service that a consumer can buy independently from any other service, provided that the bundling constraints are satisfied. Each value activity is therefore priced separately. The price for the eventual service bundle will be composed from the prices of each of the component services of the bundle.

\section{Matching needs with services}

Matching is a three-step process: (1) Elaborate desired consequences, (2) Identify benefits (service properties creating consequences) and the services that contain them, and (3) Construct service bundles (considering supplier constraints) Figure 2 shows this reasoning as a tree. A generalized form of this tree is the consumer-oriented service catalogue, used by an intermediary party, or the consumer.

\subsection{Elaborate desired consequences}

Identify wants. The matching process starts with finding one or multiple wants, derived from a stated consumer need. For example, a consumer who has the need to communicate with someone else directly, but who is at a remote distance, may have VoIP or Instant messaging as a want. Usually, to satisfy this need, a consumer wants either VoIP or Instant Messaging but not both.

Identify desired consequences that motivate the wants. The found want serves as a bootstrap in finding out what the consumer really wants in terms of consequences (cf. 2) So, we suppose that the consumer has a first comprehensive idea of a solution (the found want). While reasoning, we use constraints imposed on consequences of wants. For instance, some consequences of a want exclude each other, such as two different audio quality levels; and these two depend on the consequence hear and speak voice.

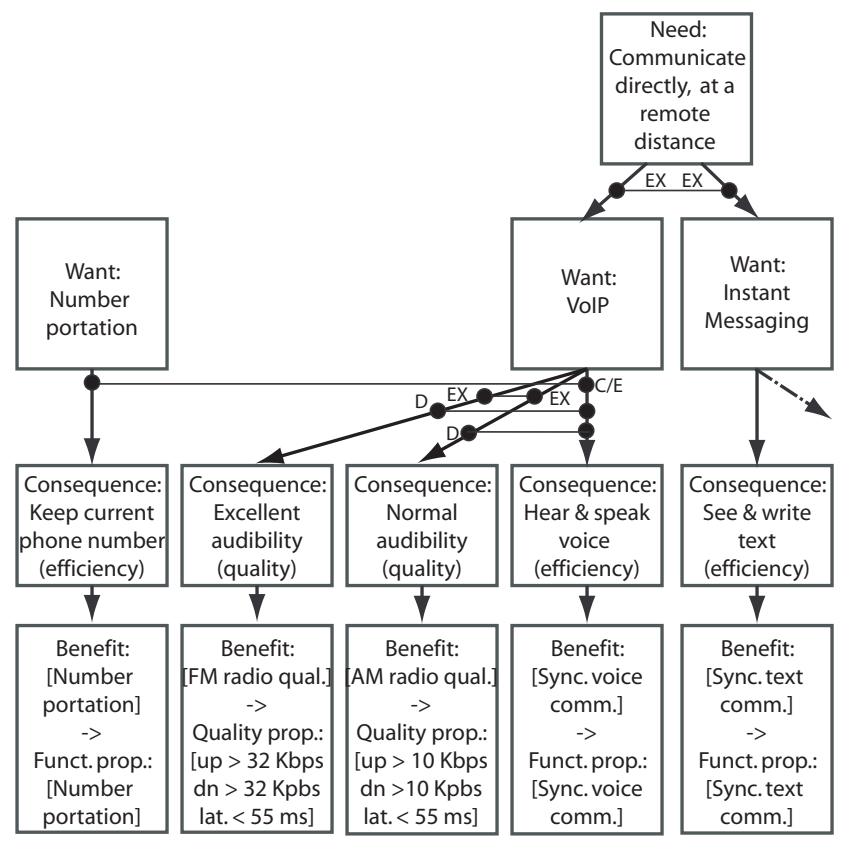

Figure 2. Reasoning process for matching consumer needs with available services.

Prioritize consequences. The consumer then assigns a priority to each consequence, using a MoSCoW-list [3]. We describe this process in detail elsewhere [6]. After prioritization, we are in a position to zoom in on consequences with high priority only.

Elaborate wants. Then we ask for additional wants and consequences. The typical question to ask is "if you want $\mathrm{X}$, you perhaps want Y too". In the running example, Number portation is an enhancing want, i.e. for this consumer the consequences of number portation enhance those of VoIP. The reasoning to find additional desirable consequences proceeds by kind of consumer value (e.g. efficiency, quality, beauty, ..., cf. [11]). The found elaborated set of consequences is again prioritized using the MoSCoW approach explained before.

\subsection{Identify benefits and the services that contain them}

We now consult the service catalogues to find services that can realize the desired consumer consequences. Efficiency consumer values map to desired functionality. For example, the efficiency value Hear \& speak voice maps to the desired benefit Synchronous voice communication, which matches with the functional service property Synchronous voice communication. Quality consumer values 


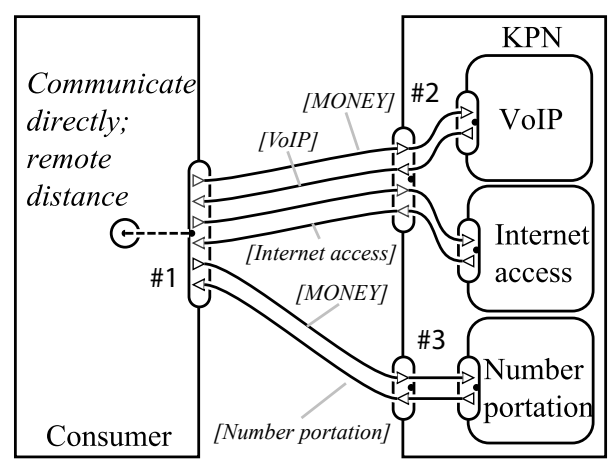

Figure 3. A service bundle by KPN

map to service qualities. For instance, the quality value $E x$ cellent audibility imposes certain criteria on certain bandwidth and latency (desired benefits) and these can match with qualities of services.

\subsection{Construct service bundles}

We now apply supplier-side bundling constraints as listed in the service catalogues, to come up with service bundles that suppliers can actually deliver. The service catalogues tell us that VoIP requires Internet access, from the same supplier in the case of KPN. The catalogues also tell us that number portation, which our consumer wants, always is bundled with VoIP from the same supplier as the supplier of number portation. This is a technical constraint imposed by suppliers and is not motivated by consumer values; the analysis in figure 2 shows that the consumer is not concerned with who provides number portation.

Based on the selected services, we can build an $e^{3}$ value model. representing the network of consumer and supplier(s) for the selected service. We can the do the standard commercial sustainability assessment of value networks that is offered by $e^{3}$-value [7] to analyze whether the service provisioning is sustainable for the enterprises. This introduces a final decision making process for the supplier network as well as for the consumer: The suppliers must assess whether they can earn money by participating in this service provision, but the consumer will assess whether she prefers one bundle over another based on price.

\section{Discussion and Further Work}

This paper adds marketing-based service matching techniques to our previous work. We have used our approach to help KPN structure their e-service catalogue. This is an initial proof-of-concept, but we plan to do more action research in the VITAL project ${ }^{1}$. We will investigate op-

\footnotetext{
${ }^{1}$ http://www.vital-project.org/
}

timization of the service value network to various criteria, e.g. commercial sustainability, or consumer value. Also, we need to formalize the construction of a consumer need tree (figure 2), to develop software tools for this process. A last interesting topic is how to put the found e-service bundle into operation, as our aim so far has been to select the bundle based on commercial and value considerations only.

Acknowledgments. We want to thank Leo Stout and Ron van der Kwaak from KPN for useful comments on the case presented in this paper. This research has been partly funded by the NWO-STW Jacquard programme as the project VITAL under number 638.003.407.

\section{References}

[1] J. Arndt. How broad should the marketing concept be? Journal of Marketing, 42(1):101-103, January 1978.

[2] Z. Baida. Software-aided Service Bundling - Intelligent Methods \& Tools for Graphical Service Modeling. $\mathrm{PhD}$ thesis, Vrije Universiteit, Amsterdam, NL, 2006.

[3] Beynon-Davies, Carne, Mackay, and Tudhope. Rapid application development (RAD): an empirical review. European Journal of Information Systems, 8(3):211-223, 1999.

[4] M. Bossworth. Solution Selling: Creating Buyers in Difficult Markets. Irwin, 1995.

[5] S.-Y. Choi, D. O. Stahl, and A. B. Whinston. The Economics of Doing Business in the Electronic Marketplace. MACMillan Technical Publishing, Indianapolis, IN, 1997.

[6] S. de Kinderen and J. Gordijn. Reasoning about substitute choices and preference ordering in e-services. Submitted, downloadable via http://www.e3value.com/bibquery/?key=VoIPCaseStudy2008, 2008.

[7] J. Gordijn and H. Akkermans. E3-value: Design and evaluation of e-business models. IEEE Intelligent Systems, 16(4):11-17, 2001.

[8] J. Gordijn, S. Kinderen, de, and R. Wieringa. Value-driven service matching. Technical report, Vrije Universiteit Amsterdam, 2008. http://docs.e3value.com/bibtex/pdf/NeedsRE08.pdf.

[9] C. Gunter, E. Gunter, M. Jackson, and P. Zave. A reference model for requirements and specifications. IEEE Software, 17(3):37-43, May/June 2000.

[10] J. Gutman. A means-end chain model based on consumer categorization processes. Journal of Marketing, 46(2):6072, Spring 1982.

[11] M. Holbrook. Consumer Value: A Framework for Analysis and Research. Routledge, 1999.

[12] P. Kotler. Marketing Management. Prentice Hall, 2000.

[13] R. Normann. Service Management: Strategy and Leadership in Service Business. Wiley, 2000. Third edition.

[14] T. Reynolds and J. Gutman. Laddering theory, method, analysis and interpretation. Journal of Advertising Research, 28(3):11-31, February/March 1988. 